Published in final edited form as:

Semin Dial. 2018 May ; 31(3): 258-267. doi:10.1111/sdi.12694.

\title{
Hemodialysis-induced Cardiovascular Disease
}

\author{
Shadi Ahmadmehrabi ${ }^{1}$ and W. H. Wilson Tang ${ }^{2,3,4}$ \\ ${ }^{1}$ Cleveland Clinic Lerner College of Medicine at Case Western Reserve University, Cleveland, $\mathrm{OH}$ \\ 2Department of Cardiovascular Medicine, Heart and Vascular Institute, Cleveland Clinic, \\ Cleveland $\mathrm{OH}$ \\ ${ }^{3}$ Center for Clinical Genomics, Cleveland Clinic, $\mathrm{OH}$ \\ ${ }^{4}$ Department of Cellular and Molecular Medicine, Lerner Research Institute, Cleveland Clinic, \\ Cleveland, $\mathrm{OH}$
}

\section{Abstract}

More than half of all deaths among ESRD patients are due to cardiovascular disease (CVD).

Cardiovascular changes secondary to renal dysfunction, including fluid overload, uremic cardiomyopathy, secondary hyperparathyroidism, anemia, altered lipid metabolism, and accumulation of gut microbiota-derived uremic toxins like trimethylamine $\mathrm{N}$-oxidase (TMAO), contribute to the high risk for CVD in the ESRD population. In addition, conventional hemodialysis (HD) itself poses myocardial stress and injury on the already compromised cardiovascular system in uremic patients. This review will provide an overview of cardiovascular changes in chronic kidney disease (CKD) and ESRD, a description of reported mechanisms for HD-induced myocardial injury, comparison of HD with other treatment modalities in the context of CVD, and possible management strategies.

\section{Introduction}

In the United States, there are more than 675,000 patients with end stage renal disease (ESRD), costing the Medicare system more than $\$ 32$ billion annually. ${ }^{1}$ There are more than 400,000 patients on hemodialysis (HD) and despite advancements in treatment, hospitalization rates and mortality remain high and quality of life is poor. More than half of all deaths among ESRD patients are due to cardiovascular disease (CVD), with arrhythmias and cardiac arrest responsible for $38 \%$ of deaths alone. ${ }^{1}$ Interestingly, ESRD patients exhibit reverse associations with traditional CVD risk factors as the general population. Obesity, hypercholesterolemia, and hypertension paradoxically appear to be protective features, in contrast to the general population. ${ }^{2}$

The largely unexplained reverse epidemiology of CVD among ESRD patients is one indication that, despite continued advancements in understanding and managing CVD and

Address for Correspondence: W. H. Wilson Tang, MD, 9500 Euclid Avenue, Desk J3-4, Cleveland, OH 44195. Phone: (216) 444-2121, Fax: (216) 445-6165, tangw@ccf.org.

Disclosure: There are no relationships relevant to this work to disclose. 
ESRD, we do not understand the intersection of these co-morbid diseases. Additionally, the impact of renal replacement therapy (RRT) on cardiovascular function and injury is not well understood and may inadvertently be contributing to the accelerated development of Type 4 cardiorenal syndrome [CRS; chronic kidney disease (CKD) leading to an impairment of cardiac function]. This review will provide an overview of cardiovascular changes in CKD and ESRD, a description of reported mechanisms for HD-induced myocardial injury, comparison of HD with other treatment modalities in the context of CVD, and possible management strategies.

\section{Cardiovascular changes in uremic patients}

There are many changes secondary to renal dysfunction that are acknowledged to contribute to the pathophysiology of Type 4 CRS, including fluid overload, uremic cardiomyopathy, secondary hyperparathyroidism, and anemia. However, the unique physiology of cardiovascular abnormalities in dialysis patients remains poorly understood (Figure 1) Several more recently recognized factors, including altered lipid metabolism and accumulation of gut microbiota-derived uremic toxins like trimethylamine $\mathrm{N}$-oxidase (TMAO), also affect cardiovascular function in the context of renal failure. In this section, we will explore a few unique characteristics of RRT patients which leave the cardiovascular system susceptible to hemodialysis-induced injury, focusing on non-traditional factors.

\section{Anemia}

Anemia, a common complication of kidney failure mainly due to erythropoietin deficiency, is an independent risk factor for adverse cardiovascular outcome in patients on RRT. ${ }^{3}$

Responses to chronically low arterial oxygen content, including increased cardiac output and left ventricular hypertrophy, may be maladaptive in the uremic setting. ${ }^{4,5}$ Anemia also promotes cardiac ischemia through a combination of reduced oxygen delivery and endothelial dysfunction-related atherosclerosis. ${ }^{5-7}$

In addition to its cardiac effects, anemia also promotes vascular dysfunction. The resulting reduced shear stress of anemia promotes endothelial dysfunction by altering signaling in the endothelium. ${ }^{8}$ Hemoglobin variability is also associated with carotid intima-media thickness in chronic hemodialysis patients. ${ }^{9}$

Notably, although erythropoietin-stimulating agents (ESA) effectively increase hemoglobin levels, higher doses and higher hematocrit management goals have failed to show benefits in mortality in several RCTs. ${ }^{10,11}$ Secondary analyses of these trials has implicated high ESA dose or ESA resistance, rather than higher hemoglobin levels, as the cause of adverse cardiovascular event. ${ }^{12-14}$

\section{Thrombosis}

Acquired intrinsic platelet abnormalities, resulting in altered platelet recruitment to the subendothelial surface, have repeatedly been described in the CKD population. ${ }^{15}$ Anemia and its connection to endothelial dysfunction, described previously, also play a role in hemostasis pathology in renal failure patients. ${ }^{15}$ Platelets in ESRD patients have a reduced serotonin content in their granules and impaired thrombin-induced ATP release. ${ }^{16}$ Patients 
with ESRD are simultaneously at increased risk of bleeding and are in a prothrombotic state, making use of antithrombotic agents in the ESRD population complex with little clinical evidence to back therapy decisions. ${ }^{17}$

\section{Vasculopathy}

Both atherosclerosis and arteriosclerosis are predominant in uremic patients. ${ }^{18,19}$

Atherosclerosis is characterized by plaque formation in medium-sized arteries while arteriosclerosis is characterized by diffuse calcification and dilation of the medial layer of the aorta and major branches. In uremic patients, hyperparathyroidism secondary to derangements in calcium, phosphate, fibroblast growth factor 23, and vitamin D homeostasis in CKD patients leads to thickening of blood vessels. ${ }^{9}$ Hypertension also contributes to vasculopathy. Anemia also contributes to vasculopathy by decreasing nitric oxide synthesis and increasing LDL oxidation, a key step in atherosclerotic plaque formation. ${ }^{5-7}$ Calcification and atherosclerotic changes in coronary vasculature promote chronic myocardial ischemia, rather than acute syndromes, which may explain the relatively low incidence of acute myocardial infarction in this population. ${ }^{20}$

\section{Uremic Toxin Accumulation}

Since the early days of dialysis urea levels have been used to assess and guide dialysis prescriptions., Urea offers a practical measure of the effect of dialysis but is itself only a minor contributor to uremic illness. ${ }^{21}$ Identification of other, more toxic solutes has been slow and clinical practice has evolved to use $\mathrm{Kt} / \mathrm{V}_{\text {urea }}$ almost exclusively to guide dialysis therapy. ${ }^{22}$ However, $\mathrm{Kt} / \mathrm{V}_{\text {urea }}$ does not strongly correlate with clearance of other uremic toxins ${ }^{23}$ and the design of dialysis membranes is optimized for urea removal. With urea kinetics driving dialysis therapy, there is little consideration of accumulation of microbiotaderived uremic toxins such as trimethylamine-N-oxidase (TMAO) that are not routinely monitored but contribute to CVD risk. ${ }^{24}$ In addition, CKD patients exhibit a vicious cycle of uremia-induced disruption of colonic epithelial tight junctions ${ }^{25}$ leading to endotoxemia, systemic inflammation, and further susceptibility to uremic toxin accumulation.

Recently, trimethylamine-N-oxide (TMAO), a gut microbial-dependent metabolite cleared by the kidney, has been associated with CVD and increased risk of adverse cardiac events. ${ }^{24}$ In a clinical cohort of over 4,000 patients, TMAO levels predicted the risk of incident major adverse cardiovascular events independent of traditional CVD risk factors. ${ }^{26}$ In CKD patients, TMAO is both a biomarker and a renal toxin, contributing to development of renal insufficiency and portending poorer long-term survival. ${ }^{27}$ In a sub-analysis of patients from the HEMO study, TMAO levels were associated with higher risk of cardiac death, sudden cardiac death, first cardiovascular event, and any-cause death. ${ }^{23}$ Although TMAO is a small molecule that is readily cleared by dialysis, $\mathrm{Kt} / \mathrm{V}_{\text {urea }}$ does not correlate with TMAO clearance. ${ }^{23}$ TMAO levels reach multiples of normal much greater than those for urea in ESRD. ${ }^{28}$ More focused monitoring of uremic toxin accumulation may allow for better prediction, and prevention, of cardiovascular complications for hemodialysis patients. Table 1 summarizes major studies on TMAO in the dialysis population. 
While TMAO is dialyzable and may be cleared better with more frequent dialysis, ${ }^{29} \mathrm{P}$ creosol sulfate and indoxyl sulfate are protein-bound, non-dialyzable uremic toxins which induce vascular inflammation, endothelial dysfunction, and vascular calcification. In dialysis patients, p-creosol sulfate and indoxyl sulfate are 17 and 54 times higher than healthy subjects. ${ }^{30}$ In both dialysis and non-dialysis patients, free p-creosol sulfate concentrations are associated with CVD and mortality. In analysis of HEMO Study participants, there was no correlation between p-cresol sulfate and indoxyl sulfate and cardiovascular outcomes; however, among patients with low albumin levels, there was such an association. ${ }^{31}$

AST-120 is an orally administered binder that can adsorb small molecule uremic toxins and is used internationally to slow the progression of renal disease and improve uremic symptoms. ${ }^{32}$ However, compliance is limited as AST-120 has a high pill burden. In the United States, two randomized clinical trials, EPPIC-1 and EPPIC-2, adding AST-120 to standard therapy in patients with moderate to severe CKD did not significantly delay disease progression. ${ }^{33}$ AST-120 may be effective in preventing cardiovascular complications specifically; however, this has not been studied in depth. ${ }^{34}$

\section{Cardiotonic steroid accumulation}

Cardiotonic steroids are among many compounds that accumulate in renal failure and affect cardiovascular function. ${ }^{35}$ These compounds inhibit sodium-potassium ATP-ase, affecting intra- and extra-cellular volume, electrolyte hemostasis, and myocardial contractility, elevating blood pressure. These cardiotonic steroids include endogenous digoxin and digitoxin, ouabain (EO), and marinobufagenin (MBG) and are increased in a variety of clinical conditions, including renal failure, hypertension, and congestive heart failure. ${ }^{36}$ In addition to $\mathrm{Na} / \mathrm{K}$-ATPase activity, CTSs also affect intracellular activity to produce dosedependent changes in gene expression, which indicates CTSs as a novel class of steroid hormones. 37

In rats, partial nephrectomy increases plasma $\mathrm{MBG}$, which stimulates fibroblast collagen production and causes fibrosis while immunization against MBG results in less cardiac hypertrophy, diastolic dysfunction, and cardiac fibrosis. ${ }^{38}$ In the setting of heart failure, MBG is associated with right ventricular dysfunction and cardiac fibrosis. ${ }^{39} \mathrm{MBG}$-induced fibrosis may be mitigated by mineralocorticoid antagonists, which exhibit competitive inhibition of MBG's effect on $\mathrm{Na} / \mathrm{K}$-ATPase; in a small prospective study of resistant hypertension patients, who exhibited elevated plasma MBG and reduced $\mathrm{Na} / \mathrm{K}-\mathrm{ATPase}$ activity, spironolactone was associated with restoration of $\mathrm{Na} / \mathrm{K}$-ATPase activity, decreased arterial pressure, and decreased pulse wave velocity. ${ }^{40}$ CTSs work in conjunction with RAAS to regulate hemodynamic parameters ${ }^{41}$; their accumulation and dose-dependent long term effects on gene expression in the context of ESRD has not been studied.

\section{Cholesterol}

Current guidelines by $\mathrm{KDIGO}^{42}, \mathrm{ACC}^{2} \mathrm{AHA}^{43}$, and $\mathrm{ESC}^{44}$ recommend not initiating lipidlowering therapy in dialysis patients. These recommendations are based on several clinical trials which failed to show that statin therapy is beneficial in reducing cardiovascular mortality in the dialysis population, despite therapy being widely used to prevent 
cardiovascular events in the general population. The 4D study (Die Deutsche Diabetes Dialyse Studie) ${ }^{45}$ and AURORA study (A Study to Evaluate the Use of Rosuvastatin in Subjects on Regular Hemodialysis: An Assessment of Survival and Cardiovascular Events) ${ }^{46}$ studied statin therapy in CKD patients on dialysis while SHARP (Study of Heart and Renal Protection $)^{47}$ sampled nondialysis and dialysis CKD patients and showed a benefit in reducing atherosclerotic events with a combination of simvastatin and ezetimibe.

There is some evidence that hemodialysis patients are high "cholesterol absorbers" and low synthesizers as demonstrated by higher levels of cholestanol (a marker of intestinal cholesterol absorption) and lower levels of lathosterol (a marker of intestinal cholesterol synthesis), in which case ezetimibe may be more appropriate than statins and warrant further investigation. ${ }^{48,49}$ However, subgroup analysis of dialysis patients in the SHARP study did not show benefit of combination simvastatin and ezetimibe in reducing atherosclerotic events. ${ }^{47}$ The failure of the SHARP study, and others on statin therapy for CKD patients, may be due to under representation of late-stage renal disease patients. ${ }^{10}$ However, there is evidence that our classical understanding of cholesterol metabolism is challenged in RRT patients, and further study of lipid transport in these patients may be warranted.

Proteomics has revealed structural and functional alterations in HDL from CKD patients. Compared to healthy controls, HDL from ESRD-HD patients has been shown to be much less effective in cholesterol efflux and regulation of inflammation. ${ }^{50,51} \mathrm{HDL}$ from HD patients also promotes endothelial dysfunction via accumulation of symmetric dimthylarginine (SDMA), which is associated with increased all-cause and cardiovascular mortality ${ }^{52} \mathrm{HDL}$ with low SDMA is also $\mathrm{f}$ associated with lower mortality, which may allow SDMA to be an indicator of biologically effective HDL in CKD patients. ${ }^{52}$ It is not clear what causes the change in HDL structure and function, whether it be uremia, accumulation of other compounds, RRT, or other factors.

The structural and functional alterations in HDL in the setting of kidney failure help explain why, in contrast to the general population, high HDL-C levels are not associated with lower cardiovascular event rates among CKD patients. ${ }^{53,54}$ The relationship between HDL-C and all-cause and CV mortality has been described as U-shaped in HD patients. ${ }^{53}$ Similarly, a study of 1.7 million men has found that lower eGFR attenuates any salutary effect of HDLC. ${ }^{54}$

There is a bidirectional relationship between cholesterol and inflammation. Malnutrition and inflammation are cholesterol-lowering. In turn, cholesterol has anti-chemotactic ability and can attenuate inflammation. HDL from HD patients is less efficacious in its anti-chemotactic ability and regulation of inflammation. ${ }^{51}$ The Choices for Healthy Outcomes in Caring for ESRD study demonstrated that cardiovascular mortality increased significantly with elevated total cholesterol levels when inflammation and malnutrition were absent but decreased in the presence of these states. ${ }^{55}$ Statin treatment may increase HDL-C and inhibit the microinflammatory state in HD patients. ${ }^{56}$ Outcome data related to HDL-C levels in renal failure patients are difficult to interpret in the context of altered HDL-C functionality. Similarly, the states of inflammation and malnutrition are important to evaluate when considering the association of cholesterol levels with mortality. Further study of the effects of uremia and 
dialysis on lipid transport is warranted, which may guide clinical trials of statin therapy towards usage of outcomes dependent on HDL-C quantity and quality.

\section{Hemodialysis-induced stress and injury}

Though hemodialysis should theoretically improve cardiovascular function by correcting fluid overload and small molecule accumulation, cardiovascular mortality continues to be disproportionately high in the hemodialysis population. ${ }^{1}$ Comorbidities of diabetes and neuropathy may cause myocardial injury to remain subclinical and make assessment of CAD difficult; in one study, roughly $70 \%$ of dialysis patients with proven CAD were without angina. ${ }^{57}$

Left ventricular hypertrophy (LVH) is very common cardiac finding in dialysis patients; in one cohort study it was present in $74 \%$ of ESRD patients. ${ }^{58}$ Chronic volume overload with subsequent neurohormonal activation, the effects of AV fistulae, hypertension and uremic toxin accumulation all contribute to LVH in ESRD. LVH in turn promotes cardiac ischemia by increasing extra-coronary resistance and reducing coronary blood flow reserve, which has been demonstrated in the ESRD population. ${ }^{5960}$ In addition to LVH, interstitial fibrosis of the myocardium is commonly found in dialysis patients and is not completely explained by fluid overload; excessive RAAS activation, hyperphosphatemia, secondary hyperparathyroidism, and oxidative stress contribute to interstitial fibrosis. ${ }^{60}$ Fibrosis and LVH both increase risk of arrhythmogenesis. In addition to baseline cardiovascular complications of renal failure, there are many aspects of hemodialysis, including preparation and management and the process itself, that likely contribute to cardiovascular dysfunction, which we will review in this section.

\section{AV Fistula}

An arteriovenous (AV) fistula is the most common and preferred vascular access for chronic hemodialysis patients due to high blood flow rate, patency, and low infection risk. Compared to AV graft or a central venous catheter, an AV fistula is associated with lower all-cause and cardiovascular mortality. ${ }^{61}$ However, creation of the fistula leads to circulatory compensation for reduced vascular resistance by activation of RAAS and sympathetic systems, ultimately increasing cardiac output. In the setting of high AV access blood flow, patients have symptomatic high-output heart failure, with CO rising 7-10 L/min. A highoutput state further promotes LV hypertrophy in dialysis patients. ${ }^{62}$ The increased oxygen demand and decreased coronary blood flow caused by LV hypertrophy can lead to subendocardial myocardial ischemia after AV fistula formation. ${ }^{63}$ Congruently, patients with AV fistula closure show a decrease in both eccentric and concentric hypertrophy. ${ }^{64}$ Banding and revision to reduce AV fistula blood flow can improve cardiac structure and hemodynamics. ${ }^{65,66}$

\section{Biomaterials contact}

Dialysis clears many toxins that impair platelet function. ${ }^{15}$ However, regardless of potential correction of platelet abnormalities, dialysis inherently promotes thrombosis and inflammation, which are already prevalent in the uremic state, due to contact between blood 
and artificial surfaces of tubing and dialyzer membrane. Artificial materials are covered by a thin film of plasma proteins within seconds of exposure, altering protein conformation and leading to activation of complement and coagulation. ${ }^{67}$ Early use of complement-activating cellulose filters in hemodialysis gave rise to anaphylactoid reactions, which are largely avoided now, and significant advancements in dialyzer membrane technology have occurred since Wilhelm Kolff's ingenious use of sausage casings. ${ }^{68}$

Current dialyzer membranes, optimized for pore size manipulation and permeability are, however, hydrophobic and provide ample surface area for protein deposition. ${ }^{69}$ These membranes are highly prone to deposition of $\mathrm{IgG}, \mathrm{C} 3$, and fibrinogen, promoting complement activation and coagulation. ${ }^{69}$ Surface-modified hydrophilic membranes are available, which have lower protein-adsorptive properties, but are more expensive and less commonly used. ${ }^{70}$ In addition to material surfaces, continuous generation of gas-plasma interfaces (bubbles) in pumps and gas traps provide unsaturable surface area for protein absorption and contact activation. ${ }^{69}$

Cardiovascular event incidence is high in the first few weeks after hemodialysis initiation ${ }^{71}$ and is associated with systemic inflammation and endothelial dysfunction in hemodialysis patients. ${ }^{72} \mathrm{C}$-reactive protein and other inflammatory markers pre-dialysis are independently associated with hemodialysis-induced regional LV systolic dysfunction. ${ }^{73}$ Complement activation leading to leukocyte activation occurs in the first 30 minutes of hemodialysis sessions leading to pro-inflammatory changes in cytokine transcription profiles. ${ }^{69,71,74}$ The mechanistic link between inflammation and cardiovascular disease is not clear and involves significant crosstalk between inflammation, thrombosis, and vascular dysfunction pathways. Complement anaphylatoxin C5a, activated by hemodialysis biomaterials, results in expression of functionally active tissue factor in leukocytes ${ }^{75}$ and likely contributes to the pathogenesis of cardiovascular disease. Heparin can inhibit complement; however, this effect is not seen in the doses typically prescribed during dialysis ${ }^{69}$

\section{Hemodynamic stress}

Thrice-weekly hemodialysis has become the conventional prescription for renal replacement therapy due to feasibility, logistics, patient convenience, costs, and physiological experiments. As technology and medical practice continue to advance, dialysis sessions have been shortened and fluid removal has become more rapid. As dialysis pulls fluid from the intravascular compartment which in turn draws fluid from the interstitial fluid compartment, any mismatch in plasma removal and refill rates can lead to rapid volume contraction. Rapid volume contraction normally induces a baroreceptor-mediated reflex arc; however, uremic patients exhibit impaired baroreceptor sensitivity, which is associated with worse outcomes in dialysis patients. ${ }^{76}$ The non-physiological fluid removal by HD likely imposes hemodynamic stress on the already maladaptive cardiovascular system in uremic patients.

Vascular calcification in uremic patients also reduces the amount of reserve volume from which fluid can be drawn during hemodialysis, leaving uremic patients even more susceptible to rapid volume contraction. ${ }^{59}$ Intradialytic hypotension, a common complication of hemodialysis, is predictive of increased mortality and may reflect an overly aggressive fluid removal regimen. ${ }^{77}$ Additionally, dialysis patients typically gain a 
significant amount of fluid weight between sessions. This rapid cycling in volume status likely adds further stress on the cardiovascular system. The level of interdialytic fluid retention is associated with cardiovascular mortality in hemodialysis patients. ${ }^{78}$

\section{Vascular changes}

Levels of nitric oxide (NO), a key regulator of endothelial function which promotes vasodilation, decline during hemodialysis. ${ }^{79}$ Nitric oxide bioavailability is tightly linked with hemoglobin levels, with cell-free hemoglobin scavenging NO 1,000 times more rapidly than red blood cells. ${ }^{80,81}$ When hemoglobin escapes red blood cells, a process deemed decompartmentalization, the bioavailability of $\mathrm{NO}$ decreases dramatically, preventing endothelium signaling to smooth muscle cells. In a small prospective study $(\mathrm{n}=14)$, hemodialysis led to decompartmentalization of hemoglobin, decrease in NO, and subsequent endothelial dysfunction defined by reduction in flow-mediated dilation. ${ }^{82}$

\section{Myocardial ischemia and stunning}

Asymptomatic dynamic ST-T changes suggestive of silent ischemia during hemodialysis have been repeatedly reported; however, electrocardiograms are difficult to interpret in this population given the concomitant rapid changes in electrolyte levels. ${ }^{83,84}$ Hemodialysis also induces repolarization abnormalities, which are associated with changes in calcium levels and ultrafiltration volume..$^{85}$

Prospective, observational studies of hemodialysis patients show that hemodialysis induces acute reduction in global myocardial blood flow, with segments particularly deprived of blood flow developing right wall motion abnormalities (RWMAs). ${ }^{86,87}$ Ultrafiltration volume and reductions in systolic BP are each associated with hemodialysis-induced RWMAs; ${ }^{88}$ these results suggest that myocardial stunning occurs progressively throughout hemodialysis, almost like a dose-response curve. Age and cardiac troponin T, a marker of myocardial injury, are each associated with hemodialysis-induced RWMAs. ${ }^{88}$ In the longterm, patients with hemodialysis-induced RWMAs have significantly increased mortality ${ }^{73,88}$ and decreased ejection fraction ${ }^{88}$ compared to those not developing RWMAs during dialysis. In a small trial of 12 patients on either hemodialysis or hemodiafiltration, $100 \%$ of patients experienced some degree of segmental left ventricular dysfunction, with severity proportional to ultrafiltration rate and reduction in BP. ${ }^{89}$

\section{Therapeutic Interventions}

Intensive hemodialysis, peritoneal dialysis, and hemodiafiltration may be more effective in preventing cardiovascular complications of renal failure and renal replacement therapy than conventional hemodialysis due to slower fluid removal and/or middle-sized uremic toxin removal. Pharmacological therapy may also help mitigate adverse cardiovascular effects in ESRD patients; however, cardiovascular pharmacological therapy is also underutilized in the dialysis population, and knowledge of treatments proven in the general population do not necessarily apply to dialysis patients. 


\section{Therapy modality}

Intensive hemodialysis sessions are generally more frequent but either shorter or more prolonged than usual in duration. This may mitigate problems of aggressive fluid removal discussed previously. In one RCT, frequent nocturnal hemodialysis was associated with regression in LV mass. ${ }^{90} \mathrm{~A}$ benefit in a composite outcome of death, LV mass, and quality of life was associated with intensive hemodialysis in the Frequent Hemodialysis Network (FHN) Daily trial; however, there was insufficient evidence for significant claims about each index individually. ${ }^{91}$ Higher powered randomized clinical trials are needed in order to fully assess the potential survival benefit of intensive dialysis.

Peritoneal dialysis (PD) theoretically presents benefits over conventional hemodialysis including less systemic inflammation, better hemodynamic stability, slower fluid removal, and improved clearance of uremic toxins whose removal is treatment time dependent (eg intracellular and protein bound toxins). However, LV hypertrophy is more common and more severe in PD patients ${ }^{92}$ and HD patients may have more effective BP control. ${ }^{93} \mathrm{PD}$ fluids with reduced levels of glucose degradation products may improve membrane integrity and provide a cardiovascular benefit. ${ }^{94}$ The most recent randomized clinical trial in the United States failed to show a difference in 5-year survival between PD and HD. ${ }^{95}$

Hemodiafiltration (HF) may have a beneficial effect on left ventricular diastolic function compared to HD according to one cross-over trial. ${ }^{96}$ However, intradialytic cardiac magnetic resonance imaging on 12 patients randomly allocated to either HD or HF showed insufficient evidence for a significant difference between the two treatment modalities on cardiovascular responses to dialysis; the limited number of patients evaluated may account for the inconsistent findings ${ }^{89}$ In two recent RCTs, online hemodiafiltration showed a trend towards improved survival over low- and high-flux hemodialysis. ${ }^{97,98}$ Even more recently, the On-Line Hemodiafiltration Survival Study (ESHOL), which compared high convection volume hemodiafiltration to conventional high-flux hemodialysis, showed a $30 \%$ decrease in all-cause mortality. ${ }^{99}$

\section{Pharmacological therapy}

Many RCTs exclude ESRD patients due to complications of impaired drug metabolism and hemodynamic instability. Cardiovascular pharmacological therapy is also underutilized in the dialysis population, and knowledge of treatments proven in the general population do not necessarily apply to dialysis patients, as exhibited by RCTs on statin therapy in ESRD patients.

In a recent meta-analysis of randomized controlled trials of angiotensin-converting enzyme inhibitors (ACEIs) and angiotensin receptor blockers (ARBs) in dialysis patients, ARB therapy reduced the risk of heart failure by $33 \% .{ }^{100}$ While RAAS blockade raises concerns of hypotension and hyperkalemia, these side effects may be outweighed by potential increased survival and cardiac function. Combination ARB and ACEI therapy appears to decrease the loss of residual renal function in patients on peritoneal dialysis patients. ${ }^{100}$ There is no evidence that ARB and ACEI treatment differs with regard to myocardial infarction, stroke, cardiovascular death, and all-cause mortality. ${ }^{100}$ In an earlier meta- 
analysis, ACEI and ARB treatment individually reduced LV mass in HD patients but were not associated with reduction of cardiovascular events. ${ }^{101}$ More evidence is needed to definitively determine the utility of ACEI and ARBS in HD patients. In addition to decreasing afterload, aldosterone antagonism posits benefit in inflammation and fibrosis. ${ }^{102}$ Small studies of spironolactone versus placebo in maintenance HD patients have shown reduction in systolic blood pressure, aortic calcification, and mortality. ${ }^{103}$ Currently, two large trials of aldosterone antagonist therapy, ALCHEMIST and MiREnDa, are underway.

Hemodialysis-induced myocardial ischemia could possibly be mitigated with the use of beta-blockers, which have substantially improved survival in patients with acute coronary syndromes and heart failure. In 114 dialysis patients with dilated cardiomyopathy, carvedilol significantly improved cardiovascular mortality, LV function, and LV morphology. ${ }^{104}$ In a follow-up study, patients treated with carvedilol had a 50\% lower mortality rate than patients receiving placebo. ${ }^{105}$ Evidence for use of others beta blockers in the ESRD population has been limited, ${ }^{106}$ however, carvedilol's proven benefit on cardiac remodeling in the general population and its reported benefit thus far necessitate further study in HD patients.

\section{Conclusions}

Cardiovascular disease is highly prevalent among the ESRD and CKD population.

Cardiovascular dysfunction can be due to a myriad of factors originating from the disease pathology itself and from inadvertent effects of renal replacement therapy. Additional investigation of cardiovascular pharmacological therapeutics specifically within the dialysis population is needed to make evidence-based clinical decisions to mitigate CVD in this high-risk population. Further advancements in dialysis technology may also provide an opportunity to prevent cardiovascular disease complications of dialysis treatment.

\section{Acknowledgments}

Dr. Tang is supported by grant funding from the National Institutes of Health (R01DK106000, R01HL126827).

\section{References}

1. US Renal Data System. 2016 Annual Data Report: Epidemiology of Kidney Disease in the United States. Bethesda, MD: National Institutes of Health, National Institute of Diabetes and Digestive and Kidney Diseases; 2016. https://www.usrds.org/. Accessed July 28, 2017

2. Kalantar-Zadeh K, Block G, Humphreys MH, Kopple JD. Reverse epidemiology of cardiovascular risk factors in maintenance dialysis patients. Kidney Int. 2003; 63(3):793-808. DOI: 10.1046/j. 1523-1755.2003.00803.x [PubMed: 12631061]

3. Foley RN, Parfrey PS, Harnett JD, Kent GM, Murray DC, Barre PE. The impact of anemia on cardiomyopathy, morbidity, and and mortality in end-stage renal disease. Am J Kidney Dis Off J Natl Kidney Found. 1996; 28(1):53-61.

4. Levin A, Thompson CR, Ethier J, et al. Left ventricular mass index increase in early renal disease: impact of decline in hemoglobin. Am J Kidney Dis Off J Natl Kidney Found. 1999; 34(1):125-134. DOI: 10.1053/AJKD03400125

5. Eckardt KU. Anaemia in end-stage renal disease: pathophysiological considerations. Nephrol Dial Transplant Off Publ Eur Dial Transpl Assoc - Eur Ren Assoc. 2001; 16(Suppl 7):2-8.

6. Malyszko J. Mechanism of endothelial dysfunction in chronic kidney disease. Clin Chim Acta Int J Clin Chem. 2010; 411(19-20):1412-1420. DOI: 10.1016/j.cca.2010.06.019 
7. Boulanger CM, Amabile N, Guérin AP, et al. In vivo shear stress determines circulating levels of endothelial microparticles in end-stage renal disease. Hypertens Dallas Tex 1979. 2007; 49(4):902908. DOI: 10.1161/01.HYP.0000259667.22309.df

8. Patel TV, Mittal BV, Keithi-Reddy SR, Duffield JS, Singh AK. Endothelial Activation Markers in Anemic Non-Dialysis Chronic Kidney Disease Patients. Nephron Clin Pract. 2008; 110(4):c244c250. DOI: 10.1159/000167872 [PubMed: 18974656]

9. Ganidagli SE, Altunoren O, Erken E, et al. The relation between hemoglobin variability and carotid intima-media thickness in chronic hemodialysis patients. Int Urol Nephrol. Jul.2017 doi: 10.1007/ s11255-017-1651-6

10. Pfeffer MA, Burdmann EA, Chen C-Y, et al. A trial of darbepoetin alfa in type 2 diabetes and chronic kidney disease. N Engl J Med. 2009; 361(21):2019-2032. DOI: 10.1056/NEJMoa0907845 [PubMed: 19880844]

11. Singh AK, Szczech L, Tang KL, et al. Correction of anemia with epoetin alfa in chronic kidney disease. N Engl J Med. 2006; 355(20):2085-2098. DOI: 10.1056/NEJMoa065485 [PubMed: 17108343]

12. Koulouridis I, Alfayez M, Trikalinos TA, Balk EM, Jaber BL. Dose of erythropoiesis-stimulating agents and adverse outcomes in CKD: a metaregression analysis. Am J Kidney Dis Off J Natl Kidney Found. 2013; 61(1):44-56. DOI: 10.1053/j.ajkd.2012.07.014

13. Solomon SD, Uno H, Lewis EF, et al. Erythropoietic response and outcomes in kidney disease and type 2 diabetes. N Engl J Med. 2010; 363(12):1146-1155. DOI: 10.1056/NEJMoa1005109 [PubMed: 20843249]

14. Szczech LA, Barnhart HX, Inrig JK, et al. Secondary analysis of the CHOIR trial epoetin-alpha dose and achieved hemoglobin outcomes. Kidney Int. 2008; 74(6):791-798. DOI: 10.1038/ki. 2008.295 [PubMed: 18596733]

15. Kaw D, Malhotra D. HEMATOLOGY: ISSUES IN THE DIALYSIS PATIENT: Platelet Dysfunction and End-Stage Renal Disease. Semin Dial. 2006; 19(4):317-322. DOI: 10.1111/j. 1525-139X.2006.00179.x [PubMed: 16893410]

16. Di Minno G, Martinez J, McKean ML, De La Rosa J, Burke JF, Murphy S. Platelet dysfunction in uremia. Multifaceted defect partially corrected by dialysis. Am J Med. 1985; 79(5):552-559. [PubMed: 3933340]

17. Chunduri S, Folstad JE, Vachharajani TJ. Antithrombotic therapy in end-stage renal disease. Hemodial Int. n/a-n/a.

18. Rahn KH, Barenbrock M, Hausberg M, Kosch M, Suwelack B, Witta J. Vessel wall alterations in patients with renal failure. Hypertens Res Off J Jpn Soc Hypertens. 2000; 23(1):3-6.

19. Kuang D, You H, Ding F, et al. Intima-media thickness of the carotid artery and its correlation factors in maintenance hemodialysis patients: a cross-sectional study. Blood Purif. 2009; 28(3): 181-186. DOI: 10.1159/000227787 [PubMed: 19590185]

20. Herzog CA. Sudden cardiac death and acute myocardial infarction in dialysis patients: perspectives of a cardiologist. Semin Nephrol. 2005; 25(6):363-366. DOI: 10.1016/j.semnephrol.2005.05.003 [PubMed: 16298256]

21. Sirich, TL., Aronov, P., Meyer, TW. Therapeutic Removal of Uremic Toxins by Hemodialysis. In: Niwa, T., editor. Uremic Toxins. John Wiley \& Sons, Inc; 2012. p. 315-330.

22. Gotch FA, Sargent JA. A mechanistic analysis of the National Cooperative Dialysis Study (NCDS). Kidney Int. 1985; 28(3):526-534. [PubMed: 3934452]

23. Shafi T, Powe NR, Meyer TW, et al. Trimethylamine N-Oxide and Cardiovascular Events in Hemodialysis Patients. J Am Soc Nephrol. 2017; 28(1):321-331. DOI: 10.1681/ASN.2016030374 [PubMed: 27436853]

24. Heianza Y, Ma W, Manson JE, Rexrode KM, Qi L. Gut Microbiota Metabolites and Risk of Major Adverse Cardiovascular Disease Events and Death: A Systematic Review and Meta-Analysis of Prospective Studies. J Am Heart Assoc. 2017; 6(7):e004947.doi: 10.1161/JAHA.116.004947 [PubMed: 28663251]

25. Vaziri ND, Yuan J, Nazertehrani S, Ni Z, Liu S. Chronic kidney disease causes disruption of gastric and small intestinal epithelial tight junction. Am J Nephrol. 2013; 38(2):99-103. DOI: 10.1159/000353764 [PubMed: 23887095] 
26. Bennett BJ, de Aguiar Vallim TQ, Wang Z, et al. Trimethylamine-N-oxide, a metabolite associated with atherosclerosis, exhibits complex genetic and dietary regulation. Cell Metab. 2013; 17(1):4960. DOI: 10.1016/j.cmet.2012.12.011 [PubMed: 23312283]

27. Wilson Tang WH, Wang Z, Kennedy DJ, et al. Gut Microbiota-Dependent Trimethylamine Noxide (TMAO) Pathway Contributes to Both Development of Renal Insufficiency and Mortality Risk in Chronic Kidney Disease. Circ Res. 2015; 116(3):448-455. DOI: 10.1161/CIRCRESAHA. 116.305360 [PubMed: 25599331]

28. Hai X, Landeras V, Dobre MA, DeOreo P, Meyer TW, Hostetter TH. Mechanism of Prominent Trimethylamine Oxide (TMAO) Accumulation in Hemodialysis Patients. PLoS ONE. 2015; 10(12)doi: 10.1371/journal.pone.0143731

29. Meyer TW, Sirich TL, Fong KD, et al. Kt/Vurea and Nonurea Small Solute Levels in the Hemodialysis Study. J Am Soc Nephrol JASN. 2016; 27(11):3469-3478. DOI: 10.1681/ASN. 2015091035 [PubMed: 27026365]

30. Itoh Y, Ezawa A, Kikuchi K, Tsuruta Y, Niwa T. Protein-bound uremic toxins in hemodialysis patients measured by liquid chromatography/tandem mass spectrometry and their effects on endothelial ROS production. Anal Bioanal Chem. 2012; 403(7):1841-1850. DOI: 10.1007/ s00216-012-5929-3 [PubMed: 22447217]

31. Shafi T, Sirich TL, Meyer TW, et al. Results of the HEMO Study suggest that p-cresol sulfate and indoxyl sulfate are not associated with cardiovascular outcomes. Kidney Int. Jul.2017 doi: 10.1016/j.kint.2017.05.012

32. Ito S, Yoshida M. Protein-Bound Uremic Toxins: New Culprits of Cardiovascular Events in Chronic Kidney Disease Patients. Toxins. 2014; 6(2):665-678. DOI: 10.3390/toxins6020665 [PubMed: 24561478]

33. Schulman G, Berl T, Beck GJ, et al. Randomized Placebo-Controlled EPPIC Trials of AST-120 in CKD. J Am Soc Nephrol JASN. 2015; 26(7):1732-1746. DOI: 10.1681/ASN.2014010042 [PubMed: 25349205]

34. Nakamura T, Kawagoe Y, Matsuda T, et al. Oral ADSORBENT AST-120 decreases carotid intimamedia thickness and arterial stiffness in patients with chronic renal failure. Kidney Blood Press Res. 2004; 27(2):121-126. DOI: 10.1159/000077536 [PubMed: 15051932]

35. Hamlyn JM, Manunta P. ENDOGENOUS CARDIOTONIC STEROIDS IN KIDNEY FAILURE: A REVIEW AND A HYPOTHESIS. Adv Chronic Kidney Dis. 2015; 22(3):232-244. DOI: 10.1053/j.ackd.2014.12.005 [PubMed: 25908473]

36. Gonick HC, Ding Y, Vaziri ND, Bagrov AY, Fedorova OV. Simultaneous measurement of marinobufagenin, ouabain, and hypertension-associated protein in various disease states. Clin Exp Hypertens N Y N 1993. 1998; 20(5-6):617-627.

37. Klimanova EA, Tverskoi AM, Koltsova SV, et al. Time- and dose dependent actions of cardiotonic steroids on transcriptome and intracellular content of $\mathrm{Na}^{+}$and $\mathrm{K}^{+}$: a comparative analysis. Sci Rep. 2017; 7:srep45403.doi: 10.1038/srep45403

38. Elkareh J, Kennedy DJ, Yashaswi B, et al. Marinobufagenin stimulates fibroblast collagen production and causes fibrosis in experimental uremic cardiomyopathy. Hypertens Dallas Tex 1979. 2007; 49(1):215-224. DOI: 10.1161/01.HYP.0000252409.36927.05

39. Kennedy DJ, Shrestha K, Sheehey B, et al. Elevated Plasma Marinobufagenin, An Endogenous Cardiotonic Steroid, Is Associated With Right Ventricular Dysfunction and Nitrative Stress in Heart Failure. Circ Heart Fail. 2015; 8(6):1068-1076. DOI: 10.1161/CIRCHEARTFAILURE. 114.001976 [PubMed: 26276886]

40. Fedorova OV, Emelianov IV, Bagrov KA, et al. Marinobufagenin-induced vascular fibrosis is a likely target for mineralocorticoid antagonists. J Hypertens. 2015; 33(8):1602-1610. DOI: 10.1097/HJH.0000000000000591 [PubMed: 26136067]

41. Manunta P, Hamlyn JM, Simonini M, et al. Endogenous ouabain and the renin-angiotensinaldosterone system: distinct effects on Na handling and blood pressure in human hypertension. $\mathrm{J}$ Hypertens. 2011; 29(2):349-356. DOI: 10.1097/HJH.0b013e32833ea821 [PubMed: 20842047]

42. Wanner C, Tonelli M, the Kidney Disease: Improving Global Outcomes Lipid Guideline Development Work Group Members. KDIGO Clinical Practice Guideline for Lipid Management 
in CKD: summary of recommendation statements and clinical approach to the patient. Kidney Int. 2014; 85(6):1303-1309. DOI: 10.1038/ki.2014.31 [PubMed: 24552851]

43. Goff DC, Lloyd-Jones DM, Bennett G, et al. 2013 ACC/AHA guideline on the assessment of cardiovascular risk: a report of the American College of Cardiology/American Heart Association Task Force on Practice Guidelines. Circulation. 2014; 129(25 Suppl 2):S49-73. DOI: 10.1161/01.cir.0000437741.48606.98 [PubMed: 24222018]

44. Catapano AL, Graham I, De Backer G, et al. 2016 ESC/EAS Guidelines for the Management of Dyslipidaemias. Eur Heart J. 2016; 37(39):2999-3058. DOI: 10.1093/eurheartj/ehw272 [PubMed: 27567407]

45. Wanner C, Krane V, März W, et al. Atorvastatin in Patients with Type 2 Diabetes Mellitus Undergoing Hemodialysis. N Engl J Med. 2005; 353(3):238-248. DOI: 10.1056/NEJMoa043545 [PubMed: 16034009]

46. Fellström BC, Jardine AG, Schmieder RE, et al. Rosuvastatin and cardiovascular events in patients undergoing hemodialysis. N Engl J Med. 2009; 360(14):1395-1407. DOI: 10.1056/ NEJMoa0810177 [PubMed: 19332456]

47. Baigent C, Landray MJ, Reith C, et al. The effects of lowering LDL cholesterol with simvastatin plus ezetimibe in patients with chronic kidney disease (Study of Heart and Renal Protection): a randomised placebo-controlled trial. Lancet Lond Engl. 2011; 377(9784):2181-2192. DOI: 10.1016/S0140-6736(11)60739-3

48. Rogacev KS, Pinsdorf T, Weingärtner O, et al. Cholesterol Synthesis, Cholesterol Absorption, and Mortality in Hemodialysis Patients. Clin J Am Soc Nephrol. 2012; 7(6):943-948. DOI: 10.2215/ CJN.05170511 [PubMed: 22461539]

49. Heine GH, Rogacev KS, Weingärtner O, Marsche G. Still a reasonable goal: Targeting cholesterol in dialysis and advanced chronic kidney disease patients. Semin Dial. n/a-n/a.

50. Holzer M, Birner-Gruenberger R, Stojakovic T, et al. Uremia Alters HDL Composition and Function. J Am Soc Nephrol JASN. 2011; 22(9):1631-1641. DOI: 10.1681/ASN.2010111144 [PubMed: 21804091]

51. Yamamoto S, Yancey PG, Ikizler TA, et al. Dysfunctional High-Density Lipoprotein in Patients on Chronic Hemodialysis. J Am Coll Cardiol. 2012; 60(23):2372-2379. DOI: 10.1016/j.jacc. 2012.09.013 [PubMed: 23141484]

52. Zewinger S, Kleber ME, Rohrer L, et al. Symmetric dimethylarginine, high-density lipoproteins and cardiovascular disease. Eur Heart J. 2017; 38(20):1597-1607. DOI: 10.1093/eurheartj/ehx118 [PubMed: 28379378]

53. Moradi H, Streja E, Kashyap ML, Vaziri ND, Fonarow GC, Kalantar-Zadeh K. Elevated highdensity lipoprotein cholesterol and cardiovascular mortality in maintenance hemodialysis patients. Nephrol Dial Transplant Off Publ Eur Dial Transpl Assoc - Eur Ren Assoc. 2014; 29(8):15541562. DOI: $10.1093 /$ ndt/gfu022

54. Bowe B, Xie Y, Xian H, Balasubramanian S, Zayed MA, Al-Aly Z. High Density Lipoprotein Cholesterol and the Risk of All-Cause Mortality among U.S. Veterans. Clin J Am Soc Nephrol CJASN. 2016; 11(10):1784-1793. DOI: 10.2215/CJN.00730116 [PubMed: 27515591]

55. Liu Y, Coresh J, Eustace JA, et al. Association between cholesterol level and mortality in dialysis patients: role of inflammation and malnutrition. JAMA. 2004; 291(4):451-459. DOI: 10.1001/ jama.291.4.451 [PubMed: 14747502]

56. Tian J, Hou X, Hu L, et al. Efficacy comparison of atorvastatin versus rosuvastatin on blood lipid and microinflammatory state in maintenance hemodialysis patients. Ren Fail. 2017; 39(1):153158. DOI: 10.1080/0886022X.2016.1256309 [PubMed: 27846790]

57. Koch M, Gradaus F, Schoebel FC, Leschke M, Grabensee B. Relevance of conventional cardiovascular risk factors for the prediction of coronary artery disease in diabetic patients on renal replacement therapy. Nephrol Dial Transplant. 1997; 12(6):1187-1191. DOI: 10.1093/ndt/ 12.6.1187 [PubMed: 9198049]

58. Foley RN, Parfrey PS, Harnett JD, et al. Clinical and echocardiographic disease in patients starting end-stage renal disease therapy. Kidney Int. 1995; 47(1):186-192. DOI: 10.1038/ki.1995.22 [PubMed: 7731145] 
59. Tok D, Gullu H, Erdogan D, et al. Impaired Coronary Flow Reserve in Hemodialysis Patients: A Transthoracic Doppler Echocardiographic Study. Nephron Clin Pract. 2005; 101(4):c200-c206. DOI: 10.1159/000087579 [PubMed: 16113583]

60. Gross M-L, Ritz E. NON-CORONARY HEART DISEASE IN DIALYSIS PATIENTS: Hypertrophy and Fibrosis in the Cardiomyopathy of Uremia-Beyond Coronary Heart Disease. Semin Dial. 2008; 21(4):308-318. DOI: 10.1111/j.1525-139X.2008.00454.x [PubMed: 18627569]

61. Wasse H, Speckman RA, McClellan WM. Arteriovenous Fistula Use Is Associated with Lower Cardiovascular Mortality Compared with Catheter Use among ESRD Patients. Semin Dial. 2008; 21(5):483-489. DOI: 10.1111/j.1525-139X.2008.00467.x [PubMed: 18764794]

62. Wasse H, Singapuri MS. High-Output Heart Failure: How to Define It, When to Treat It, and How to Treat It. Semin Nephrol. 2012; 32(6):551-557. DOI: 10.1016/j.semnephrol.2012.10.006 [PubMed: 23217335]

63. Savage MT, Ferro CJ, Sassano A, Tomson CRV. The impact of arteriovenous fistula formation on central hemodynamic pressures in chronic renal failure patients: A prospective study. Am J Kidney Dis. 2002; 40(4):753-759. DOI: 10.1053/ajkd.2002.35686 [PubMed: 12324910]

64. Movilli E, Viola BF, Brunori G, et al. Long-term Effects of Arteriovenous Fistula Closure on Echocardiographic Functional and Structural Findings in Hemodialysis Patients: A Prospective Study. Am J Kidney Dis. 2010; 55(4):682-689. DOI: 10.1053/j.ajkd.2009.11.008 [PubMed: 20089339]

65. Isoda S, Kajiwara H, Kondo J, Matsumoto A. Banding a hemodialysis arteriovenous fistula to decrease blood flow and resolve high output cardiac failure: report of a case. Surg Today. 1994; 24(8):734-736. [PubMed: 7981545]

66. Bourquelot P. Access flow reduction for cardiac failure. J Vasc Access. 2016; 17(Suppl. 1):60-63. DOI: $10.5301 /$ jva.5000517

67. Nilsson B, Ekdahl KN, Mollnes TE, Lambris JD. The role of complement in biomaterial-induced inflammation. Mol Immunol. 2007; 44(1-3):82-94. DOI: 10.1016/j.molimm.2006.06.020 [PubMed: 16905192]

68. Ratner, BD. Biomaterials Science: An Introduction to Materials in Medicine. Academic Press; 2004.

69. Ekdahl KN, Soveri I, Hilborn J, Fellström B, Nilsson B. Cardiovascular disease in haemodialysis: role of the intravascular innate immune system. Nat Rev Nephrol. 2017; 13(5):285-296. DOI: 10.1038/nrneph.2017.17 [PubMed: 28239169]

70. Bonomini M, Pavone B, Sirolli V, et al. Proteomics characterization of protein adsorption onto hemodialysis membranes. J Proteome Res. 2006; 5(10):2666-2674. DOI: 10.1021/pr060150u [PubMed: 17022637]

71. Eckardt K-U, Gillespie IA, Kronenberg F, et al. High cardiovascular event rates occur within the first weeks of starting hemodialysis. Kidney Int. 2015; 88(5):1117-1125. DOI: 10.1038/ki. 2015.117 [PubMed: 25923984]

72. Ma L, Zhao S. Risk factors for mortality in patients undergoing hemodialysis: A systematic review and meta-analysis. Int J Cardiol. 2017; 238:151-158. DOI: 10.1016/j.ijcard.2017.02.095 [PubMed: 28341375]

73. Assa S, Hummel YM, Voors AA, et al. Hemodialysis-Induced Regional Left Ventricular Systolic Dysfunction: Prevalence, Patient and Dialysis Treatment-Related Factors, and Prognostic Significance. Clin J Am Soc Nephrol CJASN. 2012; 7(10):1615-1623. DOI: 10.2215/CJN. 00850112 [PubMed: 22822014]

74. Friedrich B, Alexander D, Janessa A, Häring H-U, Lang F, Risler T. Acute effects of hemodialysis on cytokine transcription profiles: evidence for C-reactive protein-dependency of mediator induction. Kidney Int. 2006; 70(12):2124-2130. DOI: 10.1038/sj.ki.5001865 [PubMed: 17063178]

75. Kourtzelis I, Markiewski MM, Doumas M, et al. Complement anaphylatoxin C5a contributes to hemodialysis-associated thrombosis. Blood. 2010; 116(4):631-639. DOI: 10.1182/ blood-2010-01-264051 [PubMed: 20424189]

76. Robinson TG, Carr SJ. Cardiovascular autonomic dysfunction in uremia. Kidney Int. 2002; 62(6): 1921-1932. DOI: 10.1046/j.1523-1755.2002.00659.x [PubMed: 12427117] 
77. Agarwal R. How can we prevent intradialytic hypotension? Curr Opin Nephrol Hypertens. 2012; 21(6):593-599. DOI: 10.1097/MNH.0b013e3283588f3c [PubMed: 22914686]

78. Kalantar-Zadeh K, Regidor DL, Kovesdy CP, et al. Fluid retention is associated with cardiovascular mortality in patients undergoing long-term hemodialysis. Circulation. 2009; 119(5):671-679. DOI: 10.1161/CIRCULATIONAHA.108.807362 [PubMed: 19171851]

79. Raj DSC, Vincent B, Simpson K, et al. Hemodynamic changes during hemodialysis: Role of nitric oxide and endothelin. Kidney Int. 2002; 61(2):697-704. DOI: 10.1046/j.1523-1755.2002.00150.x [PubMed: 11849413]

80. Reiter CD, Wang X, Tanus-Santos JE, et al. Cell-free hemoglobin limits nitric oxide bioavailability in sickle-cell disease. Nat Med. 2002; 8(12):1383-1389. DOI: 10.1038/nm799 [PubMed: 12426562]

81. Kim-Shapiro DB, Patel RP. Compartmentalization Is Key in Limiting Nitric Oxide Scavenging by Cell-Free Hemoglobin. Am J Respir Crit Care Med. 2016; 193(10):1072-1074. DOI: 10.1164/ rccm.201512-2481ED [PubMed: 27174473]

82. Meyer C, Heiss C, Drexhage C, et al. Hemodialysis-Induced Release of Hemoglobin Limits Nitric Oxide Bioavailability and Impairs Vascular Function. J Am Coll Cardiol. 2010; 55(5):454-459. DOI: 10.1016/j.jacc.2009.07.068 [PubMed: 20117459]

83. Zuber M, Steinmann E, Huser B, Ritz R, Thiel G, Brunner F. Incidence of arrhythmias and myocardial ischaemia during haemodialysis and haemofiltration. Nephrol Dial Transplant Off Publ Eur Dial Transpl Assoc - Eur Ren Assoc. 1989; 4(7):632-634.

84. Abe S, Yoshizawa M, Nakanishi N, et al. Electrocardiographic abnormalities in patients receiving hemodialysis. Am Heart J. 1996; 131(6):1137-1144. [PubMed: 8644592]

85. Ozportakal H, Ozkok A, Alkan O, et al. Hemodialysis-induced repolarization abnormalities on ECG are influenced by serum calcium levels and ultrafiltration volumes. Int Urol Nephrol. 2017; 49(3):509-515. DOI: 10.1007/s11255-016-1472-z [PubMed: 27943168]

86. McIntyre CW, Burton JO, Selby NM, et al. Hemodialysis-induced cardiac dysfunction is associated with an acute reduction in global and segmental myocardial blood flow. Clin J Am Soc Nephrol CJASN. 2008; 3(1):19-26. DOI: 10.2215/CJN.03170707 [PubMed: 18003765]

87. Dasselaar JJ, Slart RHJA, Knip M, et al. Haemodialysis is associated with a pronounced fall in myocardial perfusion. Nephrol Dial Transplant Off Publ Eur Dial Transpl Assoc - Eur Ren Assoc. 2009; 24(2):604-610. DOI: 10.1093/ndt/gfn501

88. Burton JO, Jefferies HJ, Selby NM, McIntyre CW. Hemodialysis-induced cardiac injury: determinants and associated outcomes. Clin J Am Soc Nephrol CJASN. 2009; 4(5):914-920. DOI: 10.2215/CJN.03900808 [PubMed: 19357245]

89. Buchanan C, Mohammed A, Cox E, et al. Intradialytic Cardiac Magnetic Resonance Imaging to Assess Cardiovascular Responses in a Short-Term Trial of Hemodiafiltration and Hemodialysis. J Am Soc Nephrol. 2017; 28(4):1269-1277. DOI: 10.1681/ASN.2016060686 [PubMed: 28122851]

90. Culleton BF, Walsh M, Klarenbach SW, et al. Effect of frequent nocturnal hemodialysis vs conventional hemodialysis on left ventricular mass and quality of life: a randomized controlled trial. JAMA. 2007; 298(11):1291-1299. DOI: 10.1001/jama.298.11.1291 [PubMed: 17878421]

91. FHN Trial Group. Chertow GM, Levin NW, et al. In-center hemodialysis six times per week versus three times per week. N Engl J Med. 2010; 363(24):2287-2300. DOI: 10.1056/NEJMoa1001593 [PubMed: 21091062]

92. Enia G, Mallamaci F, Benedetto FA, et al. Long-term CAPD patients are volume expanded and display more severe left ventricular hypertrophy than haemodialysis patients. Nephrol Dial Transplant Off Publ Eur Dial Transpl Assoc - Eur Ren Assoc. 2001; 16(7):1459-1464.

93. Lai S, Molfino A, Russo GE, et al. Cardiac, Inflammatory and Metabolic Parameters: Hemodialysis versus Peritoneal Dialysis. Cardiorenal Med. 2015; 5(1):20-30. DOI: 10.1159/000369588 [PubMed: 25759697]

94. Grantham CE, Hull KL, Graham-Brown MPM, March DS, Burton JO. The Potential Cardiovascular Benefits of Low-Glucose Degradation Product, Biocompatible Peritoneal Dialysis Fluids: A Review of the Literature. Perit Dial Int J Int Soc Perit Dial. 2017; 37(4):375-383. DOI: 10.3747/pdi.2016.00228 
95. Mehrotra R, Chiu Y-W, Kalantar-Zadeh K, Bargman J, Vonesh E. Similar outcomes with hemodialysis and peritoneal dialysis in patients with end-stage renal disease. Arch Intern Med. 2011; 171(2):110-118. DOI: 10.1001/archinternmed.2010.352 [PubMed: 20876398]

96. Czifra Á, Páll A, Kulcsár J, et al. Hemodialysis and hemodiafiltration differently modulate left ventricular diastolic function. BMC Nephrol. 2013; 14:76.doi: 10.1186/1471-2369-14-76 [PubMed: 23547981]

97. Ok E, Asci G, Toz H, et al. Mortality and cardiovascular events in online haemodiafiltration (OLHDF) compared with high-flux dialysis: results from the Turkish OL-HDF Study. Nephrol Dial Transplant Off Publ Eur Dial Transpl Assoc - Eur Ren Assoc. 2013; 28(1):192-202. DOI: $10.1093 / \mathrm{ndt} / \mathrm{gfs} 407$

98. Grooteman MPC, van den Dorpel MA, Bots ML, et al. Effect of online hemodiafiltration on allcause mortality and cardiovascular outcomes. J Am Soc Nephrol JASN. 2012; 23(6):1087-1096. DOI: 10.1681/ASN.2011121140 [PubMed: 22539829]

99. Maduell F, Moreso F, Pons M, et al. High-efficiency postdilution online hemodiafiltration reduces all-cause mortality in hemodialysis patients. J Am Soc Nephrol JASN. 2013; 24(3):487-497. DOI: 10.1681/ASN.2012080875 [PubMed: 23411788]

100. Liu Y, Ma X, Zheng J, Jia J, Yan T. Effects of angiotensin-converting enzyme inhibitors and angiotensin receptor blockers on cardiovascular events and residual renal function in dialysis patients: a meta-analysis of randomised controlled trials. Bmc Nephrol. 2017; 18:206.doi: 10.1186/s12882-017-0605-7 [PubMed: 28666408]

101. Tai DJ, Lim TW, James MT, et al. Cardiovascular effects of angiotensin converting enzyme inhibition or angiotensin receptor blockade in hemodialysis: a meta-analysis. Clin J Am Soc Nephrol CJASN. 2010; 5(4):623-630. DOI: 10.2215/CJN.07831109 [PubMed: 20133488]

102. Brown NJ. Contribution of aldosterone to cardiovascular and renal inflammation and fibrosis. Nat Rev Nephrol. 2013; 9(8):459-469. DOI: 10.1038/nrneph.2013.110 [PubMed: 23774812]

103. Suthar SD, Middleton JP. Clinical Outcomes in Dialysis Patients: Prospects for Improvement with Aldosterone Receptor Antagonists. Semin Dial. 2016; 29(1):52-61. DOI: 10.1111/sdi.12421 [PubMed: 26242304]

104. Cice G, Ferrara L, Di Benedetto A, et al. Dilated cardiomyopathy in dialysis patients-beneficial effects of carvedilol: a double-blind, placebo-controlled trial. J Am Coll Cardiol. 2001; 37(2): 407-411. [PubMed: 11216954]

105. Cice G, Ferrara L, D'Andrea A, et al. Carvedilol increases two-year survivalin dialysis patients with dilated cardiomyopathy: a prospective, placebo-controlled trial. J Am Coll Cardiol. 2003; 41(9):1438-1444. [PubMed: 12742278]

106. Agarwal R, Sinha AD, Pappas MK, Abraham TN, Tegegne GG. Hypertension in hemodialysis patients treated with atenolol or lisinopril: a randomized controlled trial. Nephrol Dial Transplant Off Publ Eur Dial Transpl Assoc - Eur Ren Assoc. 2014; 29(3):672-681. DOI: 10.1093/ndt/ gft515

107. Bain MA, Faull R, Fornasini G, Milne RW, Evans AM. Accumulation of trimethylamine and trimethylamine-N-oxide in end-stage renal disease patients undergoing haemodialysis. Nephrol Dial Transplant Off Publ Eur Dial Transpl Assoc - Eur Ren Assoc. 2006; 21(5):1300-1304. DOI: 10.1093/ndt/gfk056

108. Choi J-Y, Yoon YJ, Choi H-J, et al. Dialysis modality-dependent changes in serum metabolites: accumulation of inosine and hypoxanthine in patients on haemodialysis. Nephrol Dial Transplant. 2011; 26(4):1304-1313. DOI: 10.1093/ndt/gfq554 [PubMed: 20844182]

109. Kaysen GA, Johansen KL, Chertow GM, et al. Associations of Trimethylamine N-Oxide With Nutritional and Inflammatory Biomarkers and Cardiovascular Outcomes in Patients New to Dialysis. J Ren Nutr Off J Counc Ren Nutr Natl Kidney Found. 2015; 25(4):351-356. DOI: 10.1053/j.jrn.2015.02.006

110. Stubbs JR, House JA, Ocque AJ, et al. Serum Trimethylamine-N-Oxide is Elevated in CKD and Correlates with Coronary Atherosclerosis Burden. J Am Soc Nephrol JASN. 2016; 27(1):305313. DOI: 10.1681/ASN.2014111063 [PubMed: 26229137] 


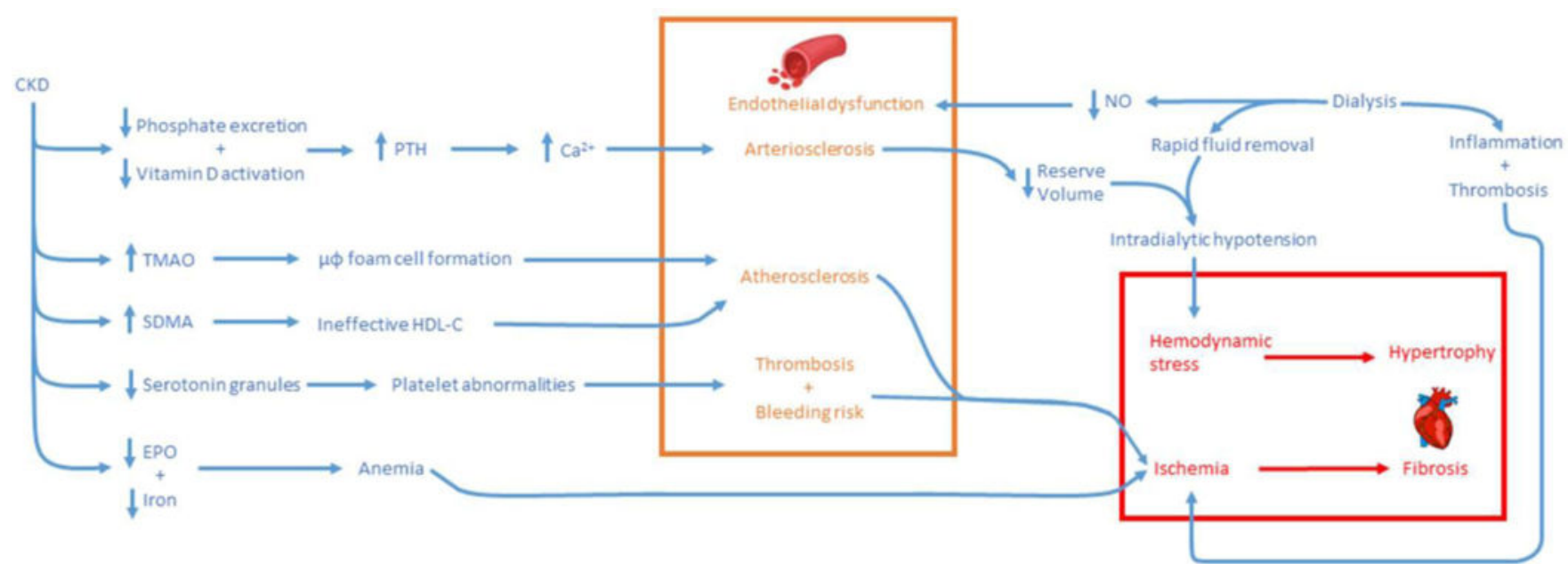

Figure 1.

Factors affecting hemodynamic-induced cardiovascular disease 


\section{Table 1}

Major studies on trimethylamine $N$-oxide (TMAO) in dialysis patients

\begin{tabular}{|c|c|c|}
\hline First author, year & Sample & Significant Findings \\
\hline Bain MA, $2006^{107}$ & $\begin{array}{l}10 \text { healthy adults } \\
10 \text { ESRD adults on HD }\end{array}$ & $\begin{array}{l}\text { Pre-dialysis plasma TMA was 2-fold higher than healthy subjects; single } \\
\text { hemodialysis session reduced TMA } 65 \%\end{array}$ \\
\hline Choi J, $2010^{108}$ & $\begin{array}{l}\text { 18:18:18 PD patients, HD patients, } \\
\text { and normal controls matched for age, } \\
\text { sex, and dialysis duration }\end{array}$ & Serum TMAO higher in dialysis patients than control group \\
\hline Kaysen GA, 2015109 & $\begin{array}{l}235 \text { HD patients } \\
\text { Pooled control sample }\end{array}$ & $\begin{array}{l}\text { Serum TMAO higher in HD patients, directly correlated with serum albumin, } \\
\text { prealbumin, creatinine, inversely correlated with } \log (\mathrm{CRP})\end{array}$ \\
\hline Stubbs J, $2016^{110}$ & 324 CKD patients & $\begin{array}{l}\text { Serum TMAO higher in dialysis patients vs healthy controls; renal } \\
\text { transplantation resulted in } \sim 80 \% \text { reduction; TMAO an independent predictor } \\
\text { of coronary atherosclerosis burden (hazard ratio } 1.26 \text { per } 10 \mu \mathrm{M} \text { increment) }\end{array}$ \\
\hline Meyer T, $2016^{29}$ & 1281 patients from HEMO study & $\begin{array}{l}\text { High-dose HD reduced TMAO levels by } 9 \% \text { compared to standard HD; } \\
\text { achieved } \mathrm{Kt} / \mathrm{V}_{\text {urea }} \text { accounted for very little of variation in nonurea solutes }\end{array}$ \\
\hline Shafi T, $2017^{23}$ & 1232 patients from HEMO study & $\begin{array}{l}\text { TMAO associated with higher risk of cardiac death, sudden cardiac death, first } \\
\text { cardiovascular event, and any-cause death but effects differ by race }\end{array}$ \\
\hline
\end{tabular}

TMAO trimethylamine N-oxide; ESRD end stage renal disease; HD hemodialysis; PD peritoneal dialysis; TMA trimethylamine (TMAO precursor); CRP C-reactive protein 